\title{
Teachers' Thought Processes: The Case of Tunisian Gymnastic University Teachers
}

\author{
Naila Bali ${ }^{1,2}$ \\ ${ }^{1}$ High Institute of Sport and Physical Education, Ksar Saîd, University la Manouba, UMA, Tunis, Tunisia \\ ${ }^{2}$ Tunisian Research Laboratory Sport Performance Optimization, Tunis, Tunisia \\ Email: naila.bali@laposet.net
}

Received May $27^{\text {th }}, 2013$; revised June $28^{\text {th }}, 2013$; accepted July $5^{\text {th }}, 2013$

\begin{abstract}
Copyright (C) 2013 Naila Bali. This is an open access article distributed under the Creative Commons Attribution License, which permits unrestricted use, distribution, and reproduction in any medium, provided the original work is properly cited.
\end{abstract}

\begin{abstract}
Teacher's behaviour is substantially influenced and even determined by teachers' thought processes. Several studies concerning effectiveness in physical education have analysed various topics such as student engagement, curriculum time allocation, teaching methods, teacher behaviour, and teacher perceptions. However, these investigations have not applied the classroom research findings identified by other researchers. Firstly, this study explains the implied thoughts of the explained Tunisian Gymnastic University Teachers (TGUT) to teach gymnastics learning processes by analyzing their thought processes. Secondly, we included the analysis of the connection, interaction and relationship between the three topics reviewed. Thirdly, we identified and analyzed the difference between different Tunisian physical educational teachers' thoughts and its influence on their didactical practice intervention. Data were collected during 4 months of observations and interviews with six TGUT at the high institute of sport and physical education (ISSEP) in Tunisia. They all teach not mixed class in Levell (first year, BAC +1 ). These interviews were semi structured (40 minutes each) and gave teachers the opportunity to share their perspectives on broad topics such as education, teaching, and society, and also on more succinct topics such as individual students and situations that had occurred in previous lessons. The data were analyzed using constant comparison. Three topics emerged illustrate how the teachers' thinking influenced their selecting, ordering, and formulating of curriculum units, their didactic and pedagogical manoeuvring during lessons. This study revealed three major conceptions used by TGUT: 1) Teaching based on pedagogical conceptions $(7.20 \%), 2)$ Teaching based on sciences $(17.42 \%)$, and 3) Teaching based on means and practices (75.37\%). A number of themes emerged from the analysis of each case, aside to the contextualised responses of individuals. The perception of the TGUT had two consequences: 1) a didactic consequence; the TGUT plan activities that will assist students in developing only physical skills, 2) the legitimacy of the contributory sciences in training programs for student teachers of physical education (PE). Basis on this argument, we might reasonably ask what might be done to address this problem. The issues discussed in this paper will encourage teachers to reflect on their own teaching beliefs and practices and to include them in the process of planning and teaching effectiveness.
\end{abstract}

Keywords: Implied Thinking; Teachers University; Gymnastic; Didactic Intervention

\section{Introduction}

There is a general agreement that shaping competences is the aim of the teaching effectiveness (Day et al., 1999). Professional standards will be reflected in many aspects of teachingfor example, by the degree of knowledge and skills demonstrated in teaching, by the extent to which the lessons reflect careful planning, and by the extent to which control teachers emotions in the classroom. An important aspect of a successful lesson is the extent to which teachers able to create a positive environment for learning. However, many factors influence the teaching effectiveness in classroom such as the teacher's didactic action and the teacher's taught process. The relationship between the teachers' behaviour and students is mutual and affects the influence of transmission and acquisition of content. Teachers refer to ways in which arrange both the physical and social dimensions of the class in order to provide a supportive environment for teaching and learning (Wright, 2005). The teaching profession places one large external requirement on decisions that teachers have to make quickly, in isolation, and usually in varied situation. These demands put teachers in the practicability and intuition's position as indispensable resources to survive in the profession. So, these demands favour the improvement of beliefs about what do work and not in a classroom. At the same time, it seems that teachers generate their own beliefs about how to teach in their school years and these beliefs are perpetuated in their teaching practice. Thus, educational beliefs are passed on to the students (Handal, 2003).

Clark et al. (1997) summarized and synthesized the teachers' thought processes, they said in 1986 that "Even though the work of researcher is no guided by the desire to prescribe the teachers a good way of thinking because they don't need but it's very important and necessary to inform them of what passes 
in their head might be useful" (Clark \& Lambert, 1986). In this context, several authors in science of education have tried to define the nature of teaching and knowledge useful to teachers to teach well (Gauthier, 1997). Beliefs about Teaching and learning do not always directly be translated into teaching practices (Hativa et al., 2001; Mellado, 1998; Murray \& MacDonald, 1997; Simmons et al., 1999). In this line Grossman (1990) stated that beliefs represent a "conceptual map for instructional decision making" (p. 86) and Pajares (1992) asserted that modifying teachers' beliefs about teaching and learning is prerequisite to changing teachers' practices. Four major headings were organised in the literature such as teacher planning, teachers' interactive thoughts and decisions, teachers' attributions, and teachers' implicit theories. Indeed, the principal idea expressed by American researchers as Knowledge base and treatment of different concepts for teachers in this literature (i.e. Anglo-Saxon education research) researches attribute a dominant place for this. In 1990, a new paradigm was discovered in French literature: "pensée implicates" what designed "implied thinking" which suggests not imposing on the teachers of the outside education rules (as it is often the case in the training courses). The first article deals with the "teachers implied thinking concept", by the Canadian researcher Tochon, in 1993 this concept was confirmed by Gauthier's theory in 1997. However, critics go well beyond Schön's (1983) criticisms of technical rationality, because the problems they identify, the lack of care compassion, and passion in actions, can also be a problem in the epistemology of practice that Schön proposes as the new paradigm for conceptualizing reflective practice. Several efforts have been made to identify the major traditions of practice in teacher education either in particular countries or more generally. These include analyses by Kirk (1986) in Australia by Harnett and Naish (1980) in the UK and by FeimanNemser (1990) in the US. It is an indication of the newness of this field that most of the work has been done since 1976 .

In Tunisia few studies have reported this paradigm. In this context, we identified only one thesis by Jlidi (2001), other same paradigm carried out by Ben Abderrahman, (2005) in a precedent study specially on a thesis we related this paradigm in physical education (Bali, 2010). Until now, no study examined the insufficiency and the increasing complexity of the subject matter of teacher thinking research coupled with the relevance and timeliness of this topic. For purely practical reasons, we argue and we encourage working on the implied thoughts on physical activity teachers and especially on Tunisian gymnastics teachers.

\section{Method}

\section{Study Protocol}

\section{Procedure}

First, permission was granted by the University Institutional Review Board, Tunisian Ministry of sports, Principals of ISSEP and gymnastic teachers to conduct the current study. Next, the researcher visited PE classes, explained steps of the study and video recording process to the teachers and the students, the confidentiality of video recording, and supervised/answered students questions.

In this empirical study, teachers' thinking is studied in different contexts. Firstly, we analysed the teachers' thought processes of the TGUT. We used a sample consisting of 06 TGUT at ISSEP in Tunisia. These TGUT were teaching not mixed class Level1 (first year, BAC +1 ). We had chosen this level for two reasons: the students had the same level at the first year at university and to compare result with other previous research (Bali, 2005).

\section{Participants}

The participants in this empirical study (Table 1) were six volunteer TGUT of the total of twelve solicited TGUT worked in high institutes of sports and physical education (ISSEP) in Tunisia; (there is only 3 ISSEP in Tunisia including only 12 TGUT teaching level 1). All TGUT participated in this study; were studied in different contexts and worked in ISSEP that is a Public high institute of sports and physical education in Tunisia. Participants were selected to vary demographic and occupational characteristics of the teachers, including speciality, sportive experience, and years of experience in coaching and year of experience in teaching presented in Table 1. They were recruited from 3 Sports Higher Institute of sports (Tunis, Kef and Sfax). The sample of participants was consisted by these TGUT who was teaching Levell (first year, BAC +1 ). The choice of this level is because the students had the same level and to compare result with those of other previous research (Bali, 2005). All participants had accepted to be video recorded during a practical session and interviewed.

Participants were not remunerated for participating in the research. They were not informed of the purpose and design of the research and written informed consent obtained from each of them. The research proposal was approved by the ethics board of Sports Ministry.

\section{Interview Procedure}

One week after the video recording sessions observing teaching practices of TGUT (step1), a personal semi-structured interview was then performed. A pilot study was conducted with two teachers to modify the question items of the interview, before being conducted with each of these observed and recorded teachers. These interviews were conducted with six TGUT working in the (ISSEP) (step 2). Given the nature of the research, all the interviews conducted with TGUT were semistructured interviews. According to the principles of the semidirective interview (Mucchielli, 1976), the interview guide may slightly change due to data collected by the observations of teaching practices in these subjects interviewed but without deviating from the main thesis. The duration was scheduled for 40 - 60 minutes, according to the same considerations, the duration varied slightly from one subject to another.

The interview contained the following predetermined openended questions: 1) what are the designs that are generally

Table 1.

The characteristics of TGUT sample.

\begin{tabular}{cc}
\hline & Tunisian Gymnastic University Teacher \\
\hline Solicited & 12 \\
Recorded & 08 \\
Recorded and interviewed & 06 \\
Years of Experience & $\geq 10$ years \\
Years of practice gymnastics & between $5 \& 10$ years \\
Years of gymnastics training & between $5 \& 10$ years \\
\hline
\end{tabular}


teachers learning gymnastics gymnastic activities? 2) What are the designs that are generally teachers' gymnastics of their students' body? 3) The role of the professional experience and good teaching gymnastic. 4) What is students' attitude? What is the Error statue?

All interviews were performed at a convenient place for each participant, such as a community centres or Institute. All interviews were audio taped with agreement from the participants.

We used a Dictaphone to record the answers of teachers interviewed. The questions focus on specific teaching practices previously recorded teachers interviewed. TGUT are interviewed while leaving freedom of speech they can express themselves at their ease.

We then proceeded to the transcription (step 3) of audio recordings of semi-structured interviews individually established after the observation of each teacher to create the corpus of 200 pages and we reported in the grid (Table 2) developed by the researcher (step 4). This grid is structured into three main categories illustrated in Table 2: 1) "Teaching based on scientific considerations": Whenever the teacher said using scientific knowledge to explain or correct a gymnastic element, 2) "Teaching based on conceptions of education referring to teaching": Whenever the teacher said referring in his didactic intervention on metaphors, gestures demonstration, explanation of terms trivialized by all categories also scientific explanation that defined above and 3) "Teaching based on means and practices": Whenever the teacher said using different style of teaching, schemes, photos, media and drawings; manipulation of his/ her student's body, using good students to help the others one, technical explanation or metaphors so, all verbal or no verbal intervention in relationship with learning round off. This grid allowed us to categorize (step 5) the TGUT implicit thoughts' asked about their own teaching practices.

Finally, we involves the linking of analyzes from different investigation techniques. We crossed the data collected during the first two steps.

\section{Data Collection}

Data were collected in three phases during 4 months. The first is a pre-interview with the TGUT to constitute their biography data, such as the number of years of experience, his or her career as a gymnast and/or gymnastic coach. At this meet- ing we presented to the TGUT the various stages of this re- search about a video recording of a practice session which dealt with ordinary learning a gymnastic element which is the round off. Followed by a semi-directive interview related session recorded representing three phases of the data collection. They gave teachers an opportunity to share their perspectives on broad topics such as education, teaching, and society, and also on more succinct topics such as individual students and situa- tions that had occurred in previous lessons. Our data were ana- lyzed using constant comparison. Three themes were emerged to show how the teachers' thinking influenced their selecting, ordering, and formulating of curriculum units, their didactic and pedagogical manoeuvring during lessons.

\section{Results}

Since teaching is a very personal activity and the strategies that good teachers use to create effective lessons will depend from a number of factors such as revealed this study. Three major conceptions used by TGUT emerged from the data collection and were illustrated as categories in Table 2: 1) Teaching based on pedagogical conceptions $(7.20 \%)$, 2) Teaching based on the sciences (17.42\%) and 3) Teaching based on means and practices $(75.37 \%)$. A number of themes have emerged from the analysis of each category, aside to the contextualised responses of individuals. Each category was divided in items. This research had produced fifteen items illustrated in Table 2.

Table 2.

Didactic analysis of TGUT thought process.

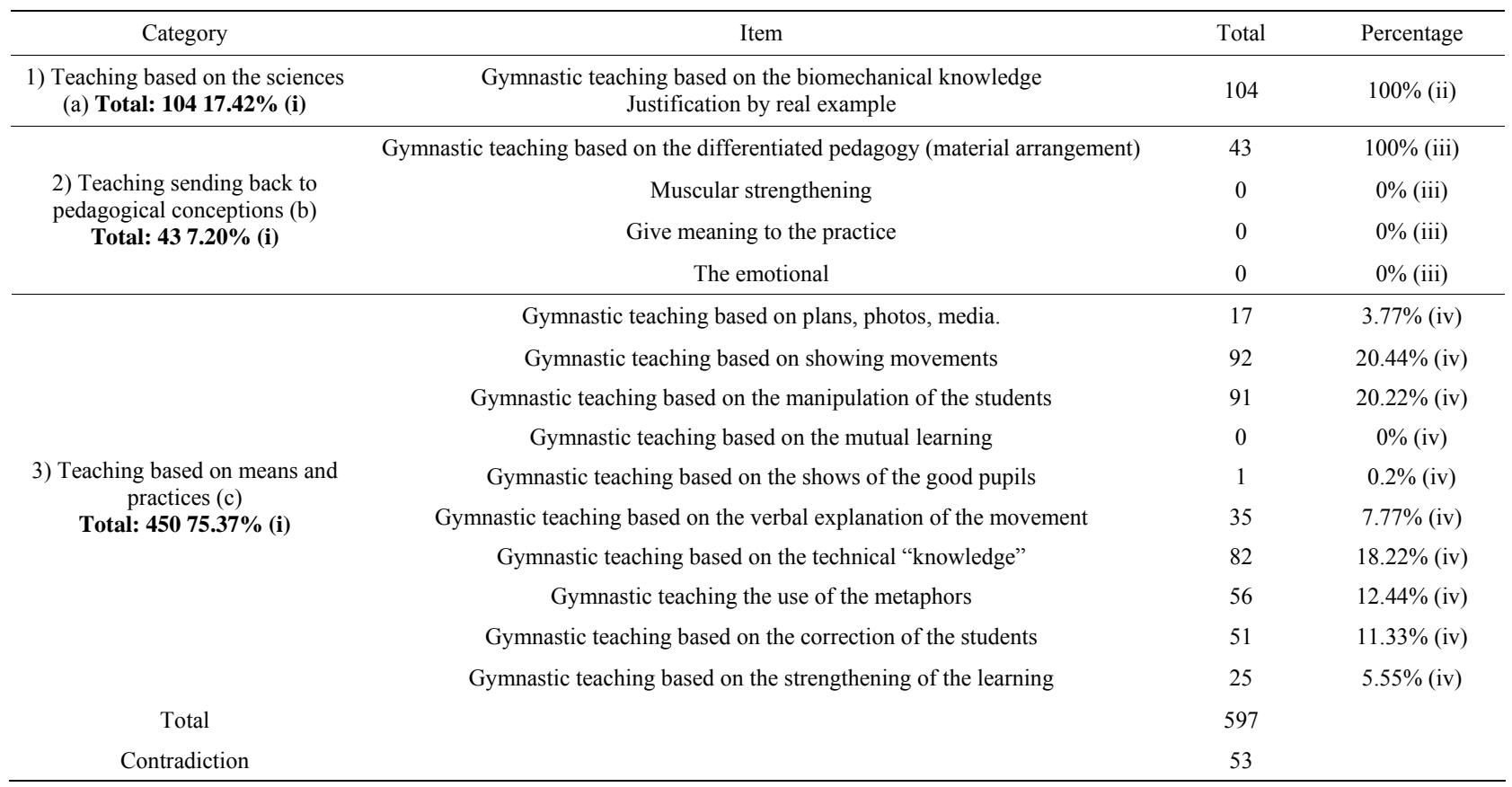




\section{Table Footnote}

1) These percentages are calculated with regard to the entire corpus.

2) These percentages are calculated with regard to the category "Teaching based on sciences".

3) These percentages are calculated with regard to the category "Teaching sending back to pedagogical conceptions".

4) These percentages are calculated with regard to the category "Teaching based on means and practices".

a) "Teaching based on scientific considerations": Whenever the teacher said using scientific knowledge to explain or correct a gymnastic element,

b) "Teaching based on conceptions of education referring to teaching": Whenever the teacher said referring in his didactic intervention on metaphors, gestures demonstration, and explanation of terms trivialized by all categories also scientific explanation that defined above.

c) "Teaching based on means and practices": Whenever the teacher said using different style of teaching, schemes, photos, media and drawings; manipulation of his/her student's body, using good students to help the others one, technical explanation or metaphors so, all verbal or no verbal intervention in relationship with learning round off.

\section{Discussion}

This study had been interested as the first one on implied thinking of university physical educational teachers in Tunisia. Thinking teacher has established a place within the international educational research. Clark (1988) claims that research on teacher thinking can improve teacher preparation by encouraging thoughtful teacher educators to ask better questions of themselves and their skills. However, until now is not so clear how studies of teacher thinking may been influenced by the quality of teacher preparation programs and teacher (Grossman, 1990 Pajares, 1992). In the present study, we present a major question that: What was Tunisian university' teachers taught about? To answer to this question, we interviewed university gymnastics teachers and we found the following results. Our data presented in Table 2 showed that interviewer teachers declared "using the scientific knowledge" (biomechanics for example) $17.42 \%$. Only $7.20 \%$ of their whole didactic interventions were based on "educational considerations". Whereas, the percentage $75.37 \%$ of their didactics' practice were based on "means and practices". When they were asked about the theoretical foundations which they use in their teaching - learning of the gymnastics, one of them asserts:

"No; I don't agree with them (the other teachers of gymnastic), because we are teaching students who will be future teachers". So if the student does not understand the biomechanical parameters and how they take place in the exercise, he cannot transmit it to his pupils in the future and he does not know where from the strengths are going to come. If he does not know for example that, from the impulse of the leg and the whip of the free leg he is going to manage to raise his body upward, how could he teach that, or like consider these elements in his future didactic practice? If he has no knowledge about this, he cannot make them communicate to his future pupils, thus he must know that the strengths result from the leg of impulse and that through sheathing body. They will be a transmission of these strengths of lower limbs to the superior members and the impulse of arms (that is the strengths of arms are passed on to legs grace). Also, the sheathing body thus if a pupil has a lax body he cannot make a success of his movement that is why it is necessary to explain for them the sheathing body and its utility; how he can communicate these knowledge to his student. If the student did not learn it during his program!! Thus we can say that the student must know this biomechanical knowledge, to be able to communicate them to his future pupils so that they can learn correctly TGUT1".

Thus, according to the first declarations of the Tunisian gymnastics teachers, the biomechanics' knowledge is important and indispensable in the learning of gymnastic elements as said another interviewed teacher states it TGUT2:

"The biomechanics is the biomechanics! And the technique in gymnastics imposes the presence of the knowledge in biomechanics! Nobody can deny the importance or the contribution of the biomechanical parameters in the learning process of the gymnastics! Because the gymnastics is a set of compound artificial movements which are made in the time and in the space: it is the strengths, the accelerations of the body that guarantee the execution of the gymnastic elements (TGUT2)".

Among the educational conceptions cited, there is also a reference to the differentiated pedagogy (100\%); (Legrand, 1975). It means according to the third interviewer TGUT3 that:

"I shall try to simplify the exercise at most to the students in difficulties! I move forward with the students who succeed and I start again with those who fail. I change educational situation, since the material exists and also spaces to work quite... (TGUT3)".

\section{And as reported one TGUT:}

"I think that almost gymnastic teacher plans instruction according to the Ministry's educational goals, curriculum, and assessment framework. They adapt instruction to take into account differences in students' learning styles, capabilities, and needs (TGUT5)".

This confirms the didactic researches (Marsenach, 1998) according to which the teachers of physical education generally use in their practices to "pragmatic knowledge" than to academic knowledge, (Cizeron, 2003; Bali, 2004, 2005; Bali et al., $2013 \mathrm{~b}$ ). In a previous study, authors showed that only $13.89 \%$ of the teachers of the ISSEP in Tunisia apply the official programs, $4.63 \%$ apply not at all the programs, $9.26 \%$ apply them little and $72.22 \%$ apply them but by changing the contents. The reference to the knowledge, according to the expression of Terrisse (2004), appears in our study as a reference to the technical knowledge, to the means and the practices adopted leave the teachers (as we shall see it later) rather than a reference to the academic knowledge.

So, this raises the problem of the "teachable object" (Marsenach, 2000): the TGUT at ISSEP trainers are expected to teach to the future professors of middle and high schools, skills of teaching in their turn the gymnastics which is a field required in the ISSEP syllabus. Yet, the gymnastics is a difficult sport's technique. It requires the analysis of the biomechanics (Piard 1988, 1991; Goirand, 1994). In order to succeed in gymnastics, 
it's necessary that the learnt gymnastics' elements are essentially based on biomechanics as confirmed one of the TGUT4 interviewed:

"Because the technique in gymnastics it is the biomechanics and if we want to understand and teach somebody a gymnastic element and make him feeling the movement and feel his body and how it is going to execute technically the wanted gymnastic element, that is going to be really difficult if he does not know a minimum about the technical and biomechanical knowledge (TGUT4)".

One interviewed teacher said:

"To me you can not teach gymnastics based on metaphors. Because in gymnastic, elements are artificial movements, complicated compounds and we do not learn natural movements (walking or running...) they need scientific knowledge and the teacher who control the scientific knowledge he will succeed in his teaching practices (TG UT3)".

The biomechanical explanation is the condition by which movements in question become teachable objects (Marsenach, 1991). However, the educational basis could moderate this educational failure. However, TGUT based their teaching on the pedagogical $(29.25 \%)$ presented here "as the differentiated pedagogy or the development) of the material" do not seem to contribute to the constitution of become "teachable objects" current practical of gymnastics.

Hebrard (2005), Bali (2010) and Bali et al. (2013b) show that the individual beginning in a sport is incapable to represent his body in movement as opposed to the confirmed sportsman who is capable of correcting his movement. This image of the body in movement really exists and cannot be the simple re- flection of the demonstration of the movement by others. It is rather about a real construction which is the synthesis of perceptive, kinaesthetic and emotional information.

$75.37 \%$ of the interviewer teachers declare basing their didactic practices on considerations "extra scientists". We connote "extra scientific considerations", every elements do not raise contributory sciences (anatomy, biomechanics, physiology, psychology) considered as the reference of the physical education, but rather the pedagogical conceptions and the means and the practices which are drawn by experience and the real-life experience of the teacher which are used by the teachers in their didactic practices (Bali et al., 2013). If, as the adage says, "teachers teach the way they have been taught" (Frank, 1990: p. 12) and the same way in Tunisia (Bali, 2005, 2010).

One of the gymnastic teachers interviewed asserts:

"The Tunisian university teachers plan activities that will assist students in developing only physical skills. Professional standards will be reflected in many aspects of their teaching (TGUT6)".

The declarations of these teachers express that these last ones based their teaching on "the gestural demonstration" (20.44\%) as said one of them:

"Ah, yes, it is imperative to show them that element. For me, it's not enough to just show them pictures patterns, as do some gym teachers (TGUT4)".

They also declare basing their teaching on the physical ma- nipulation of the students and the sensation of the movement (20.22\%). Effectively, TGUT3 declares:

“... I explain to him why and I help him to redo the movement in the upholder with my hands and making him sensitive of this movement and its fault manipulates his body manually). I say to him that the fault is at the level of shoulders". And it works with them I can even say that "touch them" have a good results for the correction and even before you start learning. if I manipulates the student, he understand what to do or at least the criterion of success this gesture is to get this feeling. Thus the student has to see the gymnastic movement and feel this movement so that he can make it. For example when he has the good elements, you can help him to stretch his legs and you say to him: it is like that, that it is necessary to perform (TG UT3)".

According to Calderhead \& Robson (1991) and Bali et al (2013b), many teachers believe that they already know what they need to be able to teach, as a result of having the opportunity to observe teachers every school day over many years. And in gymnastics, the gestural demonstration and the manipulation are very important for the learning of the pupils. "This confirms the equality of the proportions of these two items. The TGUT interviewed justify this carried attention on the kinaesthetic perceptions by the specificity of the gymnastic action which takes place most of the time outside the visual control. It is true that gymnastics in action and in rotation does not allow a visual control of the actions. Traditionally admitted, that the gymnastics requests the kinaesthetic perceptive dimension (Carnus, 2001). It would allow to understand not only the fact that the teacher goes without the visual guide, essential perceptive dimension for studying beginners, but although he makes, concerning the flexion of the head a choice which, although dictated by a concern of security, turns out to be a major didactic stumbling block. As the student cannot envisage the determining part of the visual marks, he cannot understand the consequences of the flexion of the head which he prescribes repeatedly. The Tunisian teachers of gymnastics consider the manipulation of a little active student upright, as an inescapable experience giving the student good sensations of verticality. The same group of teachers interviewed declares using metaphors $(12.44 \%)$ to explain the gymnastic movement to their students:

"Yes completely. I use many metaphors during the practical sessions, for example: to say round or hollow back I take the example of the cat. for sheathing I said: hard as "a wall" or like when a girl wants to wear "waisted pants" needs to sheathe her body (buttocks and abdomen) and for the boys I explain when someone receives a blow in the abdomen for how he does not feel the blow, brings your body like a balloon, as a ball to roll, etc. I say to them hard as "a wall" or as when a girl wants to wear waited pants needs to sheathe her body (buttocks and stomach) for the boys when somebody receives a blow in the stomach (drink the stomach) how it makes not to feel the blow, groups your body as a ball, as a ball to roll, roll to the right or to the left as a balloon etc. I give them marks that is images as I have just told it or about marks material as to look at the wall, to fix a point to the wall and to look at it, to look at the feet of his/he) companion, look at the window, etc". A declaration which seems opposite: yes! 
For me we cannot teach the gymnastics by basing itself on metaphors. Because in the gymnastics elements are artificial, compound and complicated movements we do not learn natural movements as if he/she walk or run) needs them scientific knowledge and if the teacher masters these scientific knowledge he is going to succeed in his didactic practices (TGUT4)".

We can explain the use of the metaphors by the search for the sense give meaning with regard to compared with a social reference practice): the one two shows: some pupils are in trouble at the school not because they do not possess the mental operations nor the necessary performances to master the required skills, but because they taught knowledge has no real meaning for them, because the type of questions which answer this knowledge do not make sense for them.

"Learn first, you will understand later, (TGUT4)".

We can also explain the use of the metaphors by the search for the sense (give meaning with regard to compared with a social reference practice): the one of interviewed teacher said:

"Some of the pupils are in trouble at the school not because they do not possess the mental operations nor the necessary performances to master the skills which are asked them, but because they taught knowledge has no real meaning for them, because the type of questions which answers to this knowledge does not make sense for them (TGUT5)".

And one other TGUT said to his students:

"Learns you will understand when it is correct (TGUT6)".

The first TGUT interviewed said:

These teachers declare also using "the remediation: the corrections of the students" $(11.33 \%)$ to make them learn the gymnastic gestures.

One of TGUT reported also:

"The student must do the movement by himself and I explain to him his fault ... and then I correct gestural demonstration and manual handling, I think that the sensation of movement is essential (TGUT2)".

The same group of teachers say base their teachings on the verbal explanation of the movement in a very low proportion $(7.7 \%)$ while several previous studies showed that the verbal explanation helps the pupils to learn better (Bali et al., 2013a). Let us quote for example the works of Piard (1986) about the teaching of the gymnastics. We find an approach inspired by similar references. The author insists on the necessity of presenting to the learners the rational bases of orientation, containing all the necessary theoretical marks". Teachers also declare that they do not base their didactic interventions on the mutual learning (apprenticeship) of the students $(0 \%)$. They rather the strengthening's of the learning $(5.55 \%)$, in plans $(3.77 \%)$ and in the gestural show motor skills of the good pupils $(0.2 \%)$.

All these declarations confirm the observations results of the gymnastics practical sessions and confirm result of a previous study (Bali, 2010; Bali et al., 2013b). However, during the conversations we listed some contradictions in the declarations of the gymnastics teachers that we are going to analyze in the following paragraph.
These contradictions are certainly individual, but verify partially a thesis developed by Crahay (2000) according to which one; the implicit thoughts of the teachers do not establish systems of ideas (thesis developed by Tochon, 1991) but rather crumbs of ideas! It means that the teachers questioned about their didactic practices do not answer the questions of the researcher by making reference to a system of ideas beforehand constructed and thoughtful, but rather in blow by blow. What let the opportunity to all the contradictions to justify, at all costs, their didactic practices?

Wilcox (1987) suggested that PE teachers follow teaching styles and programmes that are similar to their school experience, displaying minimal appreciation for the nature and needs of students. For example, if PE was exclusively "playing games", a teachers may believe that PE is easy to teach. Consequently, students develop a "subjective warrant" (Lawson, 1983, 1986) for PE in which teaching is considered only a small component (Crum, 1990). Similarly, these types of experiences may potentially perpetuate a teaching force previously stereotyped as "rolling out the ball" (Hutchinson, 1993: p. 353).

Crum (1990) described these types of school experiences of students who pursue careers in PE teaching as more influential than PE teacher education, and perpetuate a non-teaching ideology.

\section{Conclusion}

The perception of the TGUT had two consequences: firstly a didactic one-The TGUT plan activities that will assist students in developing only physical skills. Future teachers of PE are not learning teachable objects but motor skills, devoid of any scientific knowledge. The only alternative left to them is to perpetuate the teaching of PE by "demonstration", helping to cut the motor gesture of its theoretical foundations. The second consequence refers to the legitimacy of the contributory sciences in training programs for student teachers of PE. As well as they illuminate and facilitate, through reinvestment in the field of motor learning, their legitimacy or all remain indisputable. From the moment they are useless in practice, they become cumbersome for student teachers who "learn". On the basis of this argument we might reasonably ask what might be done to address this problem.

With regard to effective teaching in the realm of physical education, studies indicate the importance of reflection (Carson, 1997; Jagger, 1989) and the evaluation of lesson effectiveness (Borich, 1996; Rink, 1993). Understanding that teacher development requires observation, analysis, and judgment about what occurs during instruction and using that information to make changes in personal teaching behaviours was a critical feature of this topic. The teachers explored ways to reflect upon their teaching performance and student learning, and also developed an understanding of how to evaluate for effectiveness.

We hope that the issues discussed in this paper will help teachers reflect on their own teaching beliefs and practices as engaged in the process of planning and teaching effectiveness.

\section{REFERENCES}

Ajzen, I., \& Fishbein, M. (1980). Understanding attitudes and predicting social behavior. Englewood Cliffs, NJ: Prentice Hall.

Ajzen, I., \& Madden, T. J. (1986). Prediction of goal-directed behavior: 
Attitudes, intentions, and perceived behavioural control. Journal of Experimental Social Psychology, 22, 453-474.

doi:10.1016/0022-1031(86)90045-4

Bali, N. (2004). Epistemological and didactic relationship between biomechanical knowledge and teaching gymnastics designs trainers and student teachers and teachers' practices, for ISSEP. Unpublished MSc Thesis, Tunis: University of Tunis.

Bali, N (2005). "Theory and practice" articulation in the training of Tunisian student physical education teachers. Journal Research and Training, 49, 135-150.

Bali, N. (2010). Didactic practices of gymnastic teachers in relation with their teacher thinking. Comparative study in Tunisia and France. Unpublished Thesis, Paris: University of Paris.

Bali, N., et al. (2013a). Heterogeneity language conceptions' physical education teachers of the fourth (4th) year of primary French schools in Tunisia. IOSR Journal of Research \& Method in Education (IOSR-JRME), 1, 77-84.

Bali, N., et al. (2013b). The proceed of thinking surrounded by some French and Tunisian gymnastic teachers. IOSR Journal of Research \& Method in Education (IOSR-JRME), 2, 17-24.

Bandura, A. (1997). Self-efficacy: The exercise of control. New York: Freeman and Company.

Calder, et al. (1999) Research on teacher thinking. Thinking implied schools.

Clark, C. M. (1988). Asking the right questions about teacher preparation: Contributions of research on teacher thinking. Educational Researcher, 17, 5-12. doi:10.3102/0013189X017002005

Gernigon, Ch., et al. (2002). Peer tutoring in a physical education setting: Influence of tutor skill level on novice learners' motivation and performance. Journal of Teaching in Physical Education, 22, 105.

Cizeron, M. (2002). PE teachers' beliefs as cognitive anthropological basis of their expertise in teaching gymnastics. Ph.D. Thesis, Rennes: University of Rennes.

Lambert, C. (1986). Secrets of a successful trainer: A simplified guide for survival. New York: Wiley-Interscience.

Cohen, J. (1988). Statistical power analysis for the behavior sciences. Hillsdale, NJ: Erlbaum.

Conatser, P., Block, M., \& Gansneder, B. (2002). Aquatic instructors' beliefs toward inclusion: The theory of planned behavior. Adapted Physical Activity Quarterly, 19, 172-187.

Conkle, T. (1997). Inservice programs: What do physical educators want? Journal of Physical Education, Recreation, and Dance, 68, 50-55. doi:10.1080/07303084.1997.10605007

Cronbach, L. J. (1951). Coefficient alpha and the internal structure of tests. Psychometrika, 16, 296-334. doi:10.1007/BF02310555

Crahay, M. (2002). Teaching between succeed and understand-Implicit theories of education and thinking of expert teachers-Test of socio-constructivist cropping. In J. Donnay, \& M., Bru, Research, practice and knowledge in education (pp. 108-132). Brussels: De Boeck.

Davis, L. E., Ajzen, I., Saunders, J., \& Williams, T. (2002). The decision of African American students to complete high school: An application of the theory of planned behavior. Journal of Educational Psychology, 94, 810-819. doi:10.1037/0022-0663.94.4.810

Fishbein, M., \& Ajzen, I. (1975). Belief, attitude, intention, and behavior: An introduction to theory and research. Reading, MA: AddisonWesley.

Foran, A. (2006). Teaching outside the school: A phenomenological inquiry. Edmonton: Unpublished Ph.D. Dissertation, University of Al- berta.

Gauthier, et al. (1997). For a theory of pedagogy. Contemporary research on teacher's knowledge. Sainte-Foy: Presses of Laval University.

Goldberg, L. R., \& Velicer, W. F. (2005). Principles of factor analysis. In S. Strack (Ed.), Differentiating normal and abnormal personality (2nd ed.). New York: Springer.

Gollwitzer, D. (1993). Concept implementation interventions for intention behaviour relationships. European Review of Social Psychology, 4, 141-185. doi:10.1080/14792779343000059

Hastad, D. N., \& Lacy, A. C. (1998). Measurement and evaluation in physical education and exercise science (3rd ed.). Boston: Allyn \& Bacon.

Hopple, C., \& Graham, G. (1995). What children think, feel and know about physical fitness testing. Journal of Teaching in Physical Education, 14, 408-417.

Jaakkola, T., \& Watt, A. (2011) Finnish physical education teachers' self-reported use and perceptions of Mosston and Ashworth's teaching styles. Journal of Teaching in Physical Education, 30, 248.

Keating, X. D., Silverman, S., \& Kulinna, P. H. (2002). Preservice physical education teacher attitudes toward fitness tests and the factors influencing their attitudes. Journal of Teaching in Physical Education, 21, 193-207.

Kudláèek, M., Válková, H., Sherrill, C., Myers, B., \& French, R. (2002). An inclusion instrument based on planned behavior theory for prospective physical educators. Adapted Physical Activity Quarterly, 19, 280-299.

Martin, J. J., \& Kulinna, P. H. (2004). Self-efficacy theory and the theory of planned behavior: Teaching physically active physical education classes. Research Quarterly for Exercise and Sport, 75, 288-298. doi:10.1080/02701367.2004.10609161

Martin, J. J., \& Kulinna, P. H. (2005). A social cognitive perspective of physical activity related behavior. Journal of Teaching in Physical Education, 24, 265-281.

McCaughtry, N. (2005). The emotional dimensions of a teacher's pedagogical content knowledge: Influences on content, curriculum, and pedagogy. Development of pedagogical content knowledge: Moving from blaming students to predicting skillfulness, recognizing motor development, and understanding emotion. 22.

Nunnally, J. C. (1978). Psychometric theory (2nd ed.). New York: McGraw-Hill. Intentions and Behavior during Fitness Testing 27.

Perrenoud, Ph. (1994). Professionalization of the teacher profession, dual training and reflective practice. EPS in the Journal, 250.

Schön, D.-A. (1994). The reflective practitioner. Montreal: Editions Logics.

Sutton, S. (1998). Predicting and explaining intentions and behavior: How well are we doing? Journal of Applied Social Psychology, 28, 1317-1338. doi:10.1111/j.1559-1816.1998.tb01679.x

Tabachnick, B. G., \& Fidell, L. S. (2001). Using multivariate statistics (4th ed.). Boston: Allyn \& Bacon.

Thomas, J. R., \& Nelson, J. K. (2001). Research methods in physical activity (4th ed.). Champaign, IL: Human Kinetics.

Tochon, F. (2000). Research on teacher thinking: A paradigm maturity. French Review of Education, 133.

Zeichner, K. M., \& Tabachnick, B. R. (1981) Are the effects of university teacher education "washed out" by school experience? Journal of Teacher Education, 32, 7-11.

Wright, T. (2005). Classroom management in language education. Lavoisier: S.A.S. doi:10.1057/9780230514188 